\title{
Self-rated health as a valid indicator for health-equity analyses: evidence from the Italian health interview survey
}

\author{
Beniamino Cislaghi ${ }^{i^{*}}$ and Cesare Cislaghi
}

\begin{abstract}
Background: Self-rated health is widely considered a good indicator of morbidity and mortality but its validity for health equity analysis and public health policies in Italy is often disregarded by policy-makers. This study had three objectives. O1: To explore response distribution across dimensions of age, chronic health conditions, functional limitations and SRH in Italy. O2: To explore associations between SRH and healthcare demand in Italy. O3: To explore the association between SRH and household income.
\end{abstract}

Methods: Cross-sectional data were obtained from the 2015 Health Interview Survey (HIS) conducted in Italy. Italian respondents $(n=20,814)$ were included in logistic regression analyses. O1: associations of chronic health conditions $(\mathrm{CHC})$, functional limitations ( $\mathrm{FL}$ ), and age with self-rated health $(\mathrm{SRH})$ were tested. O2: associations of $\mathrm{CHC}$, FL, and SRH with hospitalisation (H), medical specialist consultations (MSC), and medicine use (MU) were tested. O3: associations of $\mathrm{SRH}$ and $\mathrm{CHC}$ with household income (PEI) were tested.

Results: $\mathrm{O}$ 1: $\mathrm{CHC}, \mathrm{FL}$, and age had an independent summative effect on respondents' SRH. O2: SRH predicted $\mathrm{H}$ and MSC more than $\mathrm{CHC}$; age and MU were more strongly correlated than SRH and MU. O3: SRH and PEl were significantly correlated, while we found no correlation between $\mathrm{CHC}$ and PEI.

Conclusions: Drawing from our results and the relevant literature, we suggest that policy-makers in Italy could use SRH measures to: 1) predict healthcare demand for effective allocation of resources; 2) assess subjective effectiveness of treatments; and 3) understand geosocial pockets of health inequity that require special attention.

Keywords: Self-rated health, Equity, National Health Service, Health policy, Healthcare demand, Italy, Self-rated health as a valid indicator for health-equity analyses: evidence from the Italian Health Interview Survey

\section{Background}

In spite of international consensus on the validity of Self-rated Health (SRH) as a good predictor of morbidity and mortality [1-5], health policy-makers in Italy have disregarded SRH measures to shape health-related policies, predict healthcare demand and run health equity analysis. Using data from the 2015 Health Interview Survey (HIS), this study investigates in particular whether SRH measures can be a valuable indicator for health equity analysis in the Italian national health service and potentially elsewhere too.

\footnotetext{
* Correspondence: ben.cislaghi@lshtm.ac.uk

'Department of Global Health and Development, London School of Hygiene and Tropical Medicine, 15-17 Tavistock Place, London WC1 9SH, UK Full list of author information is available at the end of the article
}

Several health population surveys include one or multiple questions on self-rated health (SRH) [2]. There is little doubt that the question used to measure SRH is meaningful to respondents [6, 7]. Evidence also exists that self-rated health is a stable concept, as it is formed in adolescence and remains highly consistent throughout adulthood so that people express the same opinion on their health when experiencing the same internal feelings [8].

However, in spite of these and more studies showing that SRH can accurately predict mortality and morbidity, its validity is still contended [9]. Part of the controversy originates from the debate on whether SRH is an accurate measure of an objective health status. SRH measures have been under the severe scrutiny of those arguing that one's understanding of their health (the "internal" view) might 
be very misaligned with the opinion of medical experts (the "external" view) [10]. Questions have been raised, for instance, on how psychological traits such as a fatalism or hypochondria [11, 12], larger cultural values and social norms [13, 14] or gender [15-17] might both influence responses to SRH questions, and limit the potential of SRH measures for cross-country comparisons. SRH measures can also sometimes show erratic trends in short-term analysis, as sometimes the data rely on a limited number of respondents, although useful insights can come from examining datasets collected over multiple years [10]. However, much of the available research suggests that the two (SRH and objective health status) are certainly related. In a seminal study, Blaxter [18] found that self-reported chronic conditions and diagnosed chronic conditions overlapped in $80 \%$ of the cases. More recently, using a large sample from five major Chinese cities, $\mathrm{Wu}$ and colleagues [19] found SRH to be largely consistent with objective health status. And before then, Haddock and colleagues [20] came to a similar conclusion on the validity of SRH analysing a cross-sectional health survey of military personnel. Other SRH-related measures, such as self-reported functional limitations, have also been found to be fairly accurate, especially when respondents have physical (as opposed to mental and social) limitations [21] and have been increasingly used to inform public health resource allocation policies [22].

Other commentators, however, have argued that the debate on SRH should not focus on whether it overlaps with diagnosed diseases. Rather, they have suggested that the discussion on the use of SRH is an ethical one, that relates to the goal of a national public health system and, potentially, to the very definition of what health is. Waller [23], for instance, argued that SRH is an extremely valuable measure of health as it measures what really matters: "Doctors can liberate patients and empower them to health rather than oppressing them with diagnosis, risk factors, and seeing problems. Focusing on self-rated health can help to empower patients" (p.110). One might go as far as to argue that it would be better for people to feel well, despite the presence of pathological conditions, than for them to feel bad in the absence of those conditions. The health system should thus increase its capacity to help people feel that "things go well with them" [24]. If a medical diagnosis cannot help to improve how one person feels or will feel in the future, why would that diagnosis be necessary? That is, why should the health system increase service demand of the people who feel well (beyond prevention purposes)? If people feel healthy, a therapy should only be necessary to prevent the worsening of their SRH in the future. Such an approach to health and healthcare - fairly controversial among Italian public health policy makers - is not new: Marinker [25] famously (and revolutionarily) asked over twenty years ago: why should we make people patients?
And, more recently, Misselbrook, Dean Emeritus of the Royal Society of Medicine, suggested that the health system should focus more on helping people be well, beyond just telling them why they are sick [26]. In this paradigm of health, where subjective health matters as the ultimate goal, the health system would need to be more concerned with people's illnesses, the experience of "unhealth ... interior to the person of the patient," rather than largely focussing on their diseases, the "pathological processes, most often physical ... [associated with] some deviation from a biological norm" [27].

\section{Study objectives}

This paper offers insights into whether SRH can be a valuable indicator for designing effective public health policies on population health and equitable access to the national health service. Data from the 2015 Health Interview Survey (HIS) were used (more details in the methods section). Three objectives, specifically, guided our analysis.

Objective 1: To explore response distribution across dimensions of age, chronic health conditions, functional limitations and SRH in Italy. The existing evidence shows great differences in what is associated with SRH, ranging from, for instance, physical exercise in Sweden [28], religiosity in the Caribbeans [29], education in Ireland [30], gender in Lithuania [31], and social capital and optimism towards life in Portugal [32]. While some evidence exists on what drives SRH in other European countries, little is known about what contributes to SRH in Italy. We looked specifically at the association between age, chronic health conditions, functional limitations and SRH, using key indicators available in the dataset to understand the independent effect of diseases (objective diagnosis of a chronic health condition) and sicknesses (functional limitations) on respondents' subjective feeling of wellbeing, while also testing the effect age as, possibly, the most important explicator factor of participants' health.

Objective 2: To explore associations between SRH and healthcare demand in Italy. Nothing in the literature exists on the validity of SRH as a measure to predict the use of healthcare services for effective resource allocation in Italy. The international literature, instead, includes some important studies on this very issue (e.g. [33-35]). A study by Hunt and colleagues, for instance, suggested that SRH measures could be a better predictor of utilization of UK health services than mortality and morbidity statistics [36], and in another study conducted in Finland, the authors found SRH to be significantly predictive of healthcare demand [1]. Within the literature on the Italian health system, age and chronic health conditions are often considered optimal proxies for predicting the volume of services provided, as they are found to be strongly correlated with healthcare 
demand [37], but, as we mentioned, there is no reference to $\mathrm{SRH}$ in such literature.

Objective 3: To explore the association between SRH and household income. The association between SRH and income has been proven across several countries. Commentators suggested that they are positively correlated because money increases healthcare options and resource-deprived people often experience other forms of social inequalities that can result in social and emotional deprivation [38-41]. No evidence on the association between SRH and income in Italy is available in the international literature, yet it is critical to explore this association for policy-makers to decide whether to integrate SRH within health equity analyses to inform more equitable policies.

\section{Methods}

Sample

We used data from the Health Interview Survey (HIS) designed by EUROSTAT and conducted by ISTAT in Italy in 2015. The sample is derived from a multistage probability sample of households. The sample includes population aged 15 or over living in the territory of the country [42]. The survey includes four modules: 1) health status, 2) health care use, 3) health determinants and 4) socio-economic background variables [43]. (The full questionnaire is available at https://ec.europa.eu/ eurostat/documents/3859598/5926729/KS-RA-13-018EN.PDF/26c7ea80-01d8-420e-bdc6-e9d5f6578e7c). The percentage of those in age 15-29 not reporting good or very good health is very low (see Table 1 ). We decided thus to exclude this part of the sample to avoid unbalancing our analysis. Our sample thus included 20,814 men and women aged 30 or more.

\section{Variables}

Outcome variable was Self-Rated Health, measured in the HIS using the standardised question created by the WHO: "How is your health in general? Very good; Good; Fair [translated in Italian as 'neither good or bad']; Bad; Very bad" (question code: HS1).

We used different predictor variables for each objective. Objective 1. Covariates used in our analyses for objective 1 include age, chronic health conditions (HS2: Do you have any longstanding illness or [longstanding]

Table 1 Number of respondents and percentage in the sample reporting fair, bad or very bad self-rated health by age group

\begin{tabular}{lll}
\hline Age & Sample & Report fair/bad/very bad health \\
\hline $15-29$ & $4301[16.9 \%]$ & $272[3.2 \%]$ \\
$30+$ & $20,814[83.1 \%]$ & $7394[96.8 \%]$ \\
Total & $25,325[100 \%]$ & $8500[100 \%]$ \\
\hline
\end{tabular}

health problem?), functional limitations (HS3A: Are you limited because of a health problem in activities people usually do? Would you say you are... severely limited; limited but not severely; not limited at all) and 28 diagnosed health conditions.

Table 2 Descriptive data for participants in the sample

\begin{tabular}{|c|c|c|}
\hline & Observations & Percentage in the Sample \\
\hline \multicolumn{3}{|l|}{ Sex } \\
\hline Male & 9817 & $47.2 \%$ \\
\hline Female & 10,997 & $52.8 \%$ \\
\hline \multicolumn{3}{|l|}{ Age } \\
\hline $30-34$ & 1627 & $7.8 \%$ \\
\hline $35-39$ & 1746 & $8.4 \%$ \\
\hline $40-44$ & 2208 & $10.6 \%$ \\
\hline $45-49$ & 2301 & $11.1 \%$ \\
\hline $50-54$ & 2266 & $10.9 \%$ \\
\hline $55-59$ & 2013 & $9.7 \%$ \\
\hline $60-64$ & 1903 & $9.1 \%$ \\
\hline $65-69$ & 1883 & $9.0 \%$ \\
\hline $70-74$ & 1491 & $7.2 \%$ \\
\hline $75-79$ & 1357 & $6.5 \%$ \\
\hline $80-84$ & 1040 & $5.0 \%$ \\
\hline $85+$ & 979 & $4.7 \%$ \\
\hline \multicolumn{3}{|c|}{ Region of residence } \\
\hline North-west & 5161 & $24.8 \%$ \\
\hline North-east & 4412 & $21.2 \%$ \\
\hline Centre & 4182 & $20.1 \%$ \\
\hline South & 4913 & $23.6 \%$ \\
\hline Islands & 2146 & $10.3 \%$ \\
\hline \multicolumn{3}{|l|}{ PEl quintiles } \\
\hline 1 (Poorest) & 3566 & $17.0 \%$ \\
\hline 2 & 4013 & $19.1 \%$ \\
\hline 3 & 4250 & $20.2 \%$ \\
\hline 4 & 4515 & $21.5 \%$ \\
\hline 5 (Richest) & 4680 & $22.3 \%$ \\
\hline \multicolumn{3}{|l|}{ Better SRH } \\
\hline Very good & 3295 & $15.8 \%$ \\
\hline Good & 10,125 & $48.6 \%$ \\
\hline Total better SRH & 13,420 & $64.5 \%$ \\
\hline \multicolumn{3}{|l|}{ Worse SRH } \\
\hline Fair & 5313 & $25.5 \%$ \\
\hline Bad & 1638 & $7.9 \%$ \\
\hline Very bad & 443 & $2.1 \%$ \\
\hline Total worse SRH & 7394 & $35.5 \%$ \\
\hline Total & 20,814 & $100 \%$ \\
\hline
\end{tabular}


Table 3 Response distribution percentage for self-rated health and chronic health conditions, and for self-rated health and functional limitations

\begin{tabular}{|c|c|c|c|c|c|}
\hline \multirow[t]{3}{*}{ Self-rated health } & \multicolumn{2}{|c|}{ Chronic health conditions } & \multicolumn{3}{|c|}{ Functional limitations } \\
\hline & \multicolumn{2}{|c|}{ Cohen's $K=.502 p<0.001$} & \multicolumn{3}{|c|}{ Cohen's K $=.349 p<0.001$} \\
\hline & Yes & No & Severe & Non-severe & No \\
\hline Better & $33.1 \%$ & $82.9 \%$ & $8.6 \%$ & $27.7 \%$ & $82.8 \%$ \\
\hline (very well, well) & $(5.137)$ & $(2.247)$ & $(1.763)$ & (3.128) & $(2.412)$ \\
\hline Worse & $66.9 \%$ & $17.1 \%$ & $91.4 \%$ & $72.3 \%$ & $17.2 \%$ \\
\hline (fair, bad, very bad) & $(7.675)$ & (13.109) & $(1.929)$ & $(1.929)$ & $(14.023)$ \\
\hline
\end{tabular}

Objective 2. Covariates used for objective 2 included hospitalisation (H02B: In the past 12 months (prior to the survey interview) how many times have you been admitted to hospital as a day patient?), consultation of medical or surgical specialist (AM5: During the past four weeks, how many times did you consult a specialist on your own behalf?) and medicine use (MD1: During the past two weeks (prior to the interview), have you used any medicines that were prescribed for you by a doctor?).

Objective 3. Covariates used for objective 3 included age, sex, geographical residence and "personal equivalent income" (PEI). PEI is an indicator obtained dividing household disposable income by the number of household members [44, 45]. In our analysis, we used PEI quintiles to create a dichotomous variable. In the first group (higher PEI) we included individuals within the highest two PEI quintiles ( $40 \%$ of the entire sample) and in the second group (lower PEI) we included individuals in the remaining three PEI quintiles (60\%).

\section{Statistical methods}

Several logistic regression models and descriptive cross-tabulations were used. The dependant variable is the SRH response converted into a dichotomous variable: better (reports of very good and good health) and worse (reports of fair, bad, and very bad health). As others did before (e.g. [46, 47]), we created a dichotomous variable, having observed stark differences in the Italian sample across the two groups of better and worse health, but less important differences within the two groups. The HIS in Italy allows response by proxy (e.g. a family member responding to the questions for someone incapacitated to

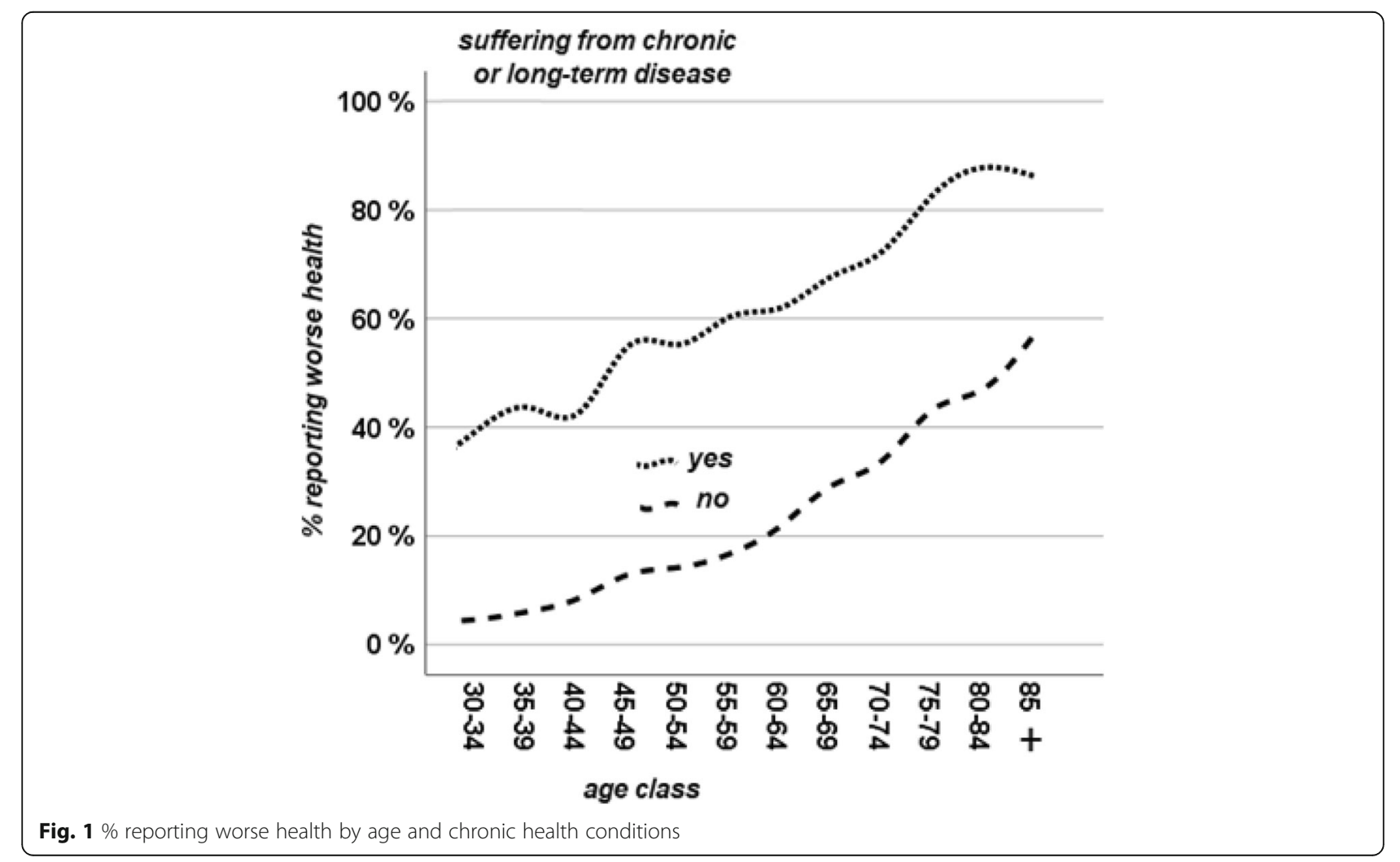


do so), which reduces presence of missing data. Despite this, there were 210 missing observations in the dataset for the SRH question (1\% of the total sample). We removed these 210 from our sample. For objective 1, we used a simple cross-tabulation to describe the association between $\mathrm{SRH}$, age, and chronic health conditions, and, separately, at the association between SRH, age, and functional limitations. For chronic health conditions there were 30 missing responses ( $0.15 \%$ of total responses); for functional limitations there were 525 missing responses $(2.5 \%$ of total responses). For objective 2, we conducted a logistic regression to test the association between SRH, age, and chronic health conditions with hospitalisation, medical examination, and prescriptions. Finally, for objective 3 we conducted a logistic regression to test the association between SRH and PEI, weighting PEI by region of residence. In all analyses, where appropriate, we controlled for age, income, sex, and region of residence.

\section{Results}

Descriptive data

Table 2 reports descriptive data on the sample included in this analysis.

\section{Main results}

Association between age, chronic health conditions, functional limitations and SRH

Table 3 reports results of the cross-tabulation used to describe the association between SRH and chronic health conditions, and the association between SRH and functional limitations.

Among those who declared to have a chronic health condition, $33.1 \%$ reported better health as compared to only $8.6 \%$ of those with severe functional limitations. Data examined by age cohorts show that both those respondents affected and unaffected by chronic health conditions are more likely to report worst health as their age increases (see Fig. 1).

Figure 1 further shows that age acts independently as a contributor to worse SRH. While approximately $40 \%$ of 30/34-years-olds with chronic health conditions report worse health, this percentage increases to more than $80 \%$ among those aged 85 and above with chronic health conditions. At the same time, respondents' SRH worsened with age at a similar trend for both those with and without a $\mathrm{CHC}$. The same is true for functional limitations: respondents' SRH became worse as they aged, independently of the severity of their limitations. (see Fig. 2).

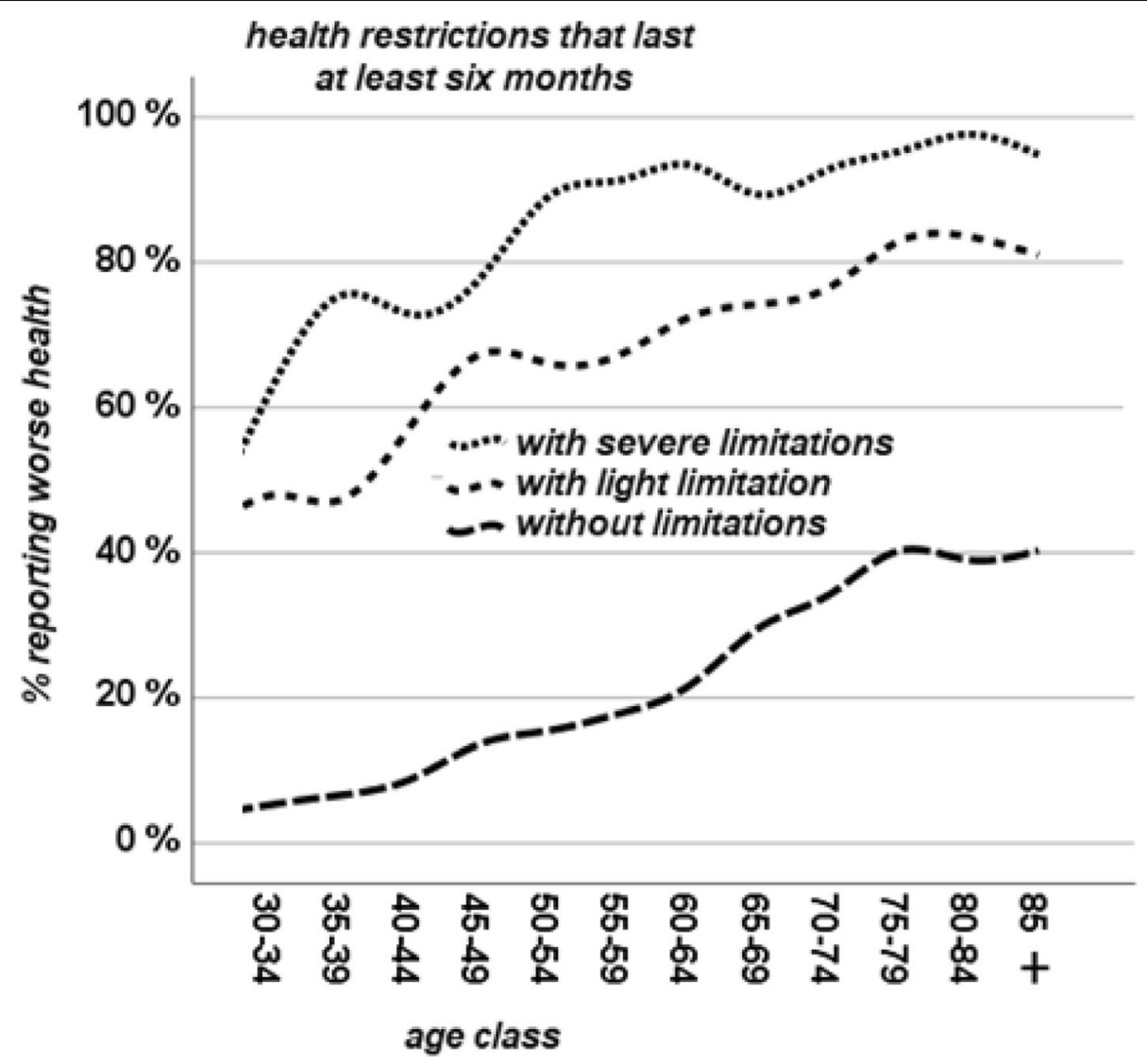

Fig. $2 \%$ reporting worse health by age and limitations 


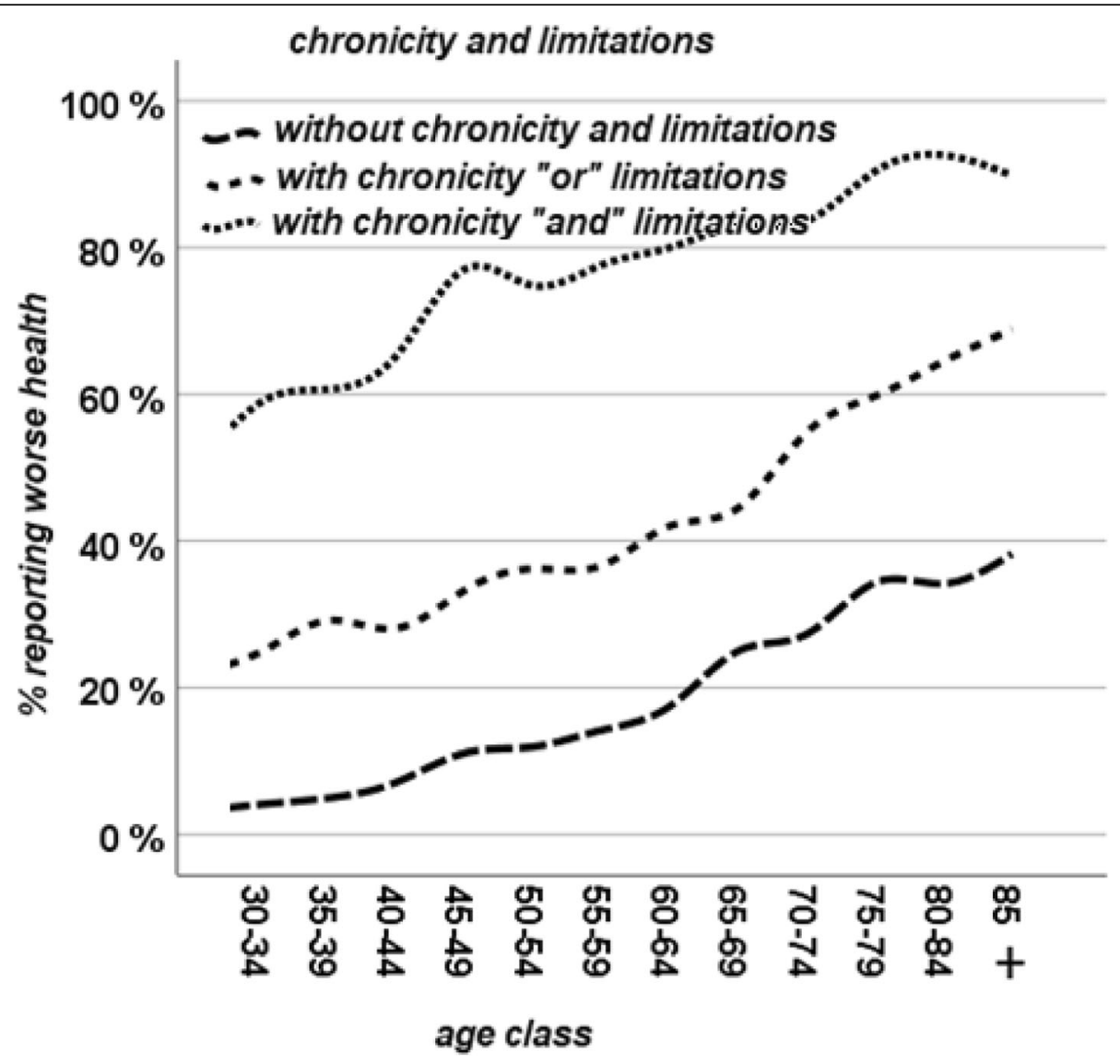

Fig. $3 \%$ reporting worse health by age and chronic health conditions and/or functional limitations

Figure 3 shows the association of any chronic health conditions and any limitations with SRH.

Having both a chronic health condition and a limitation has obviously the worst effect on SRH. However, similarly to what observed in Figs. 1 and 2, age had an independent effect on SRH, not modified by chronic health conditions (Fig. 1), functional limitations (Fig. 2) or both (Fig. 3). Chronic health conditions, functional limitations, and age have summative effect on each other, acting independently in how they influence SRH.

We looked further at the effect of SRH and health conditions. Figures 4 and 5 show, respectively, the effect that specific diagnosed health conditions have on SRH and the results of the linear regression between average age of respondents with a diagnosed health condition and the percentage of respondents with worse SRH.

Age explains $3 / 4$ of the variability in the percentage of respondents reporting worse health $(\mathrm{R} 2=.77)$. Alzheimer's disease is the condition with the highest average age (92.6\% reporting worse health), while allergies are the condition with the lowest average age (35.3\% reporting worse health). Due to the fact that certain health conditions are more likely at different ages (for instance, it is more likely to develop hypertension at older age) it was important to run the regression residuals presented in Fig. 6.

As shown in Fig. 6, there is some variability across health conditions in the extent to which age determines SRH. The Figure ranks regression residuals for each health condition. For instance, in the case of hypertension, allergies, and Alzheimer's disease, the health condition affects respondents' SRH less than their age, when compared to the regression model. In the case of depression, chronic anxiety, and hepatic cirrhosis, instead, the health condition affects respondents' SRH more than their age, when compared to the regression model. Even taking into account this variability, the regression model suggests that, overall, worse SRH is affected more by respondents' age than by their chronic conditions.

\section{Associations between SRH and healthcare demand}

Table 4 shows the result of the logistic regression testing the associations of SRH, age, chronic health conditions with 1) the number of hospital admissions in the last year (prior to the survey interview); 2) the number of medical specialist consultations in the last four weeks (prior to the interview); and 3) the drugs prescribed in the last two weeks (prior to the interview). 


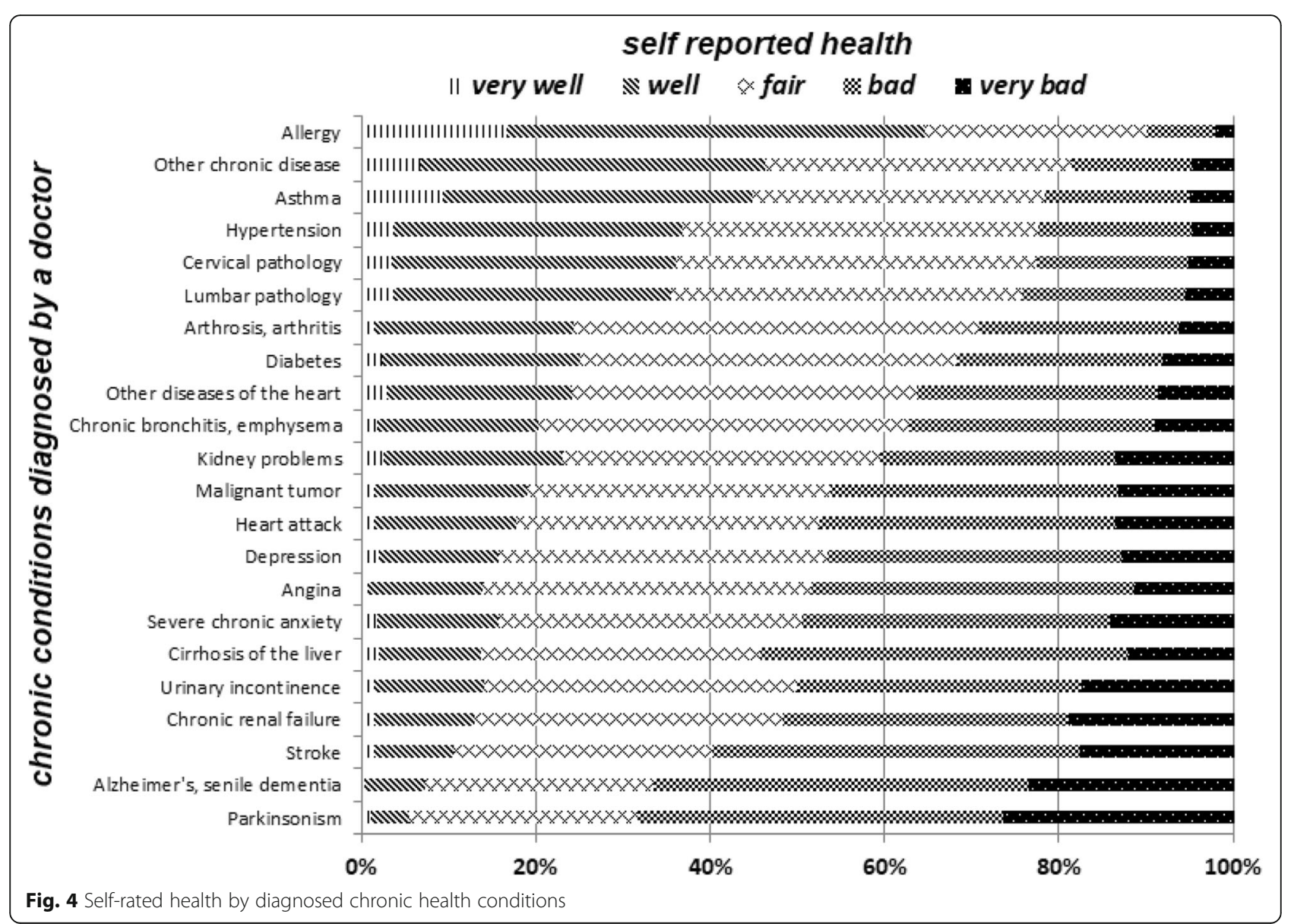

As reported in Table 4, SRH has the highest odd ratios for each of factors 1 and 2 mentioned above (with the exception of factor 3, as discussed below). More in detail, Table 4 shows that, when controlling for other factors, age played a limited role in affecting hospital admissions. The health conditions most likely to result in people's hospitalisation are cancer, cirrhosis, previous infarction, and stroke. Even though health conditions are associated with seeking hospitalisation, however, worse SRH bears the strongest association with hospitalisation than any other variables.

In the second column, Table 4 reports the factors affecting respondents' access to medical specialist examinations in the four weeks prior to the survey interview. Again, SRH is the variable that affects the most respondents' decisions to request a medical specialist examination. Interestingly, respondents with bad SRH show higher odds to access medical examinations than respondents reporting very bad SRH (possibly as the latter are already familiar with their health condition). As for the role played by diagnosed chronic health conditions, the only one that increases respondents' odds to access medical examinations are tumours.
The third column of Table 4, finally, reports odd ratios for having received a drug prescription in the last two weeks. Here, age plays a larger role than in the previous two. This is probably because, in older people, the number of prescribed drugs likely accumulates over time. Even though age affects significantly the likelihood of receiving a drug prescription, SRH still bears higher odd ratios than the diagnosed presence of chronic health conditions.

\section{Association between SRH and PEI}

HIS data reveal two possible confounders of income: region of residence and age. People living in the North-west of the country are 3 times more likely to be in the two highest PEI quintiles when compared to people living in the Southern or Islands regions. People aged $40-70$ are 2 times more likely to be in the two highest PEI quintiles than other people, with men being at slighter greater advantage over women of the same age (data not shown). Informed by this analysis, our logistical regression model tests the joint effect of age, sex, geographical residence, chronic health conditions, and SRH on the probability of 


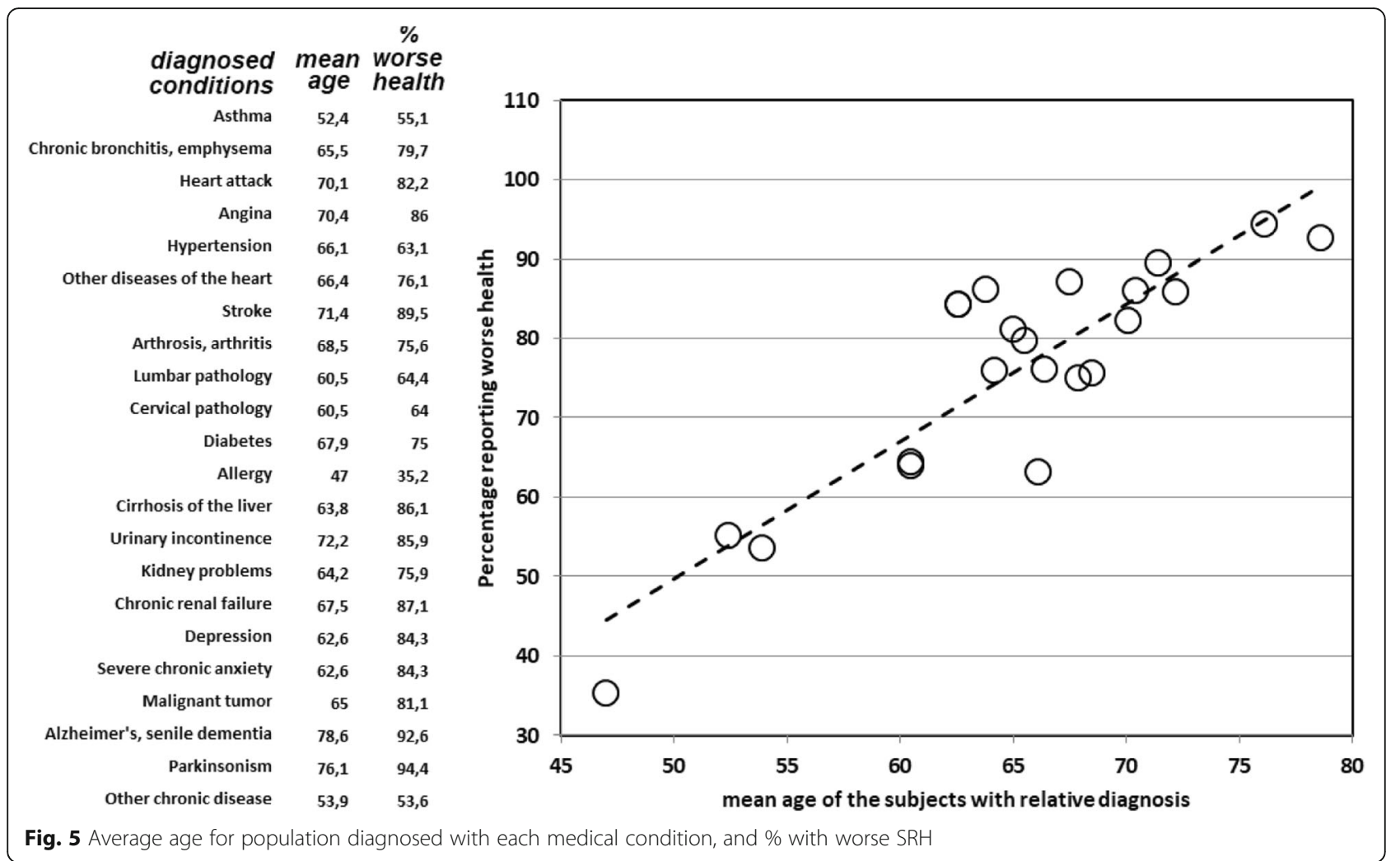

being in the lowest two PEI national quintiles. Figure 7 shows the results of this regression.

As shown in Fig. 7, the risk of having a PEI in the lowest two quintiles is not significantly different for people with any of the chronic health conditions included in Fig. 7 (with the exception of depression) when compared to people without any of those conditions. Conversely, the risk of having a PEI in the lowest two quintiles is significantly higher for those reporting worse SRH.

\section{Discussion}

We set up this study with three objectives. Objective 1 was "to explore response distribution across dimensions of age, chronic health conditions, functional limitations and SRH in Italy". We found that age, chronic health conditions, and functional limitations had an independent summative effect on SRH. Objective 2 was "to explore associations between SRH and healthcare demand in Italy". We found that, even though age affects significantly the likelihood of receiving a drug prescription, SRH predicted healthcare demand more than the diagnosed presence of chronic health conditions. Objective 3 was: "to explore the association between SRH and income". We found that SRH increased the risk of having a lower PEI more than the presence of a chronic health condition. We hypothesis this difference to be due to the fact that people with a lower PEI might struggle more to compensate for their chronic health condition. That is, we suggest that the experience of a condition (rather than the condition itself) affects more the SRH of poorer than that of richer people.

We suggest three critical implications for health policy-makers in Italy and possibly Europe at large following our result as contextualised in the relevant literatures. These implications are related to using SRH measures to: 1) predict healthcare demand for effective allocation of resources; 2) assess subjective effectiveness of treatments; and 3) understand geosocial pockets of health inequity that require special attention.

Whether SRH can be used as a predictor of service utilisation has been the subject of an intricate and unresolved debate. Some have argued that SRH measures in equations for the utilisation of healthcare are endogenous; that is, respondents might be more likely to rate their health bad if they have recently visited a doctor [22] and, for this reason, that SRH cannot be used as a prediction measure (but, rather, as post-diction measures, as people's SRH might be dependent on having visited the health service before the survey) [34]. This is a valid objection, yet the level of bias produced by the potential endogeneity of the indicator should be carefully assessed, especially since other studies have provided evidence of the usefulness of using SRH to this predictive purpose. Our findings suggest that, in 2015 in Italy, hospitalization and specialist consultations were generally less influenced by the presence of an actual 


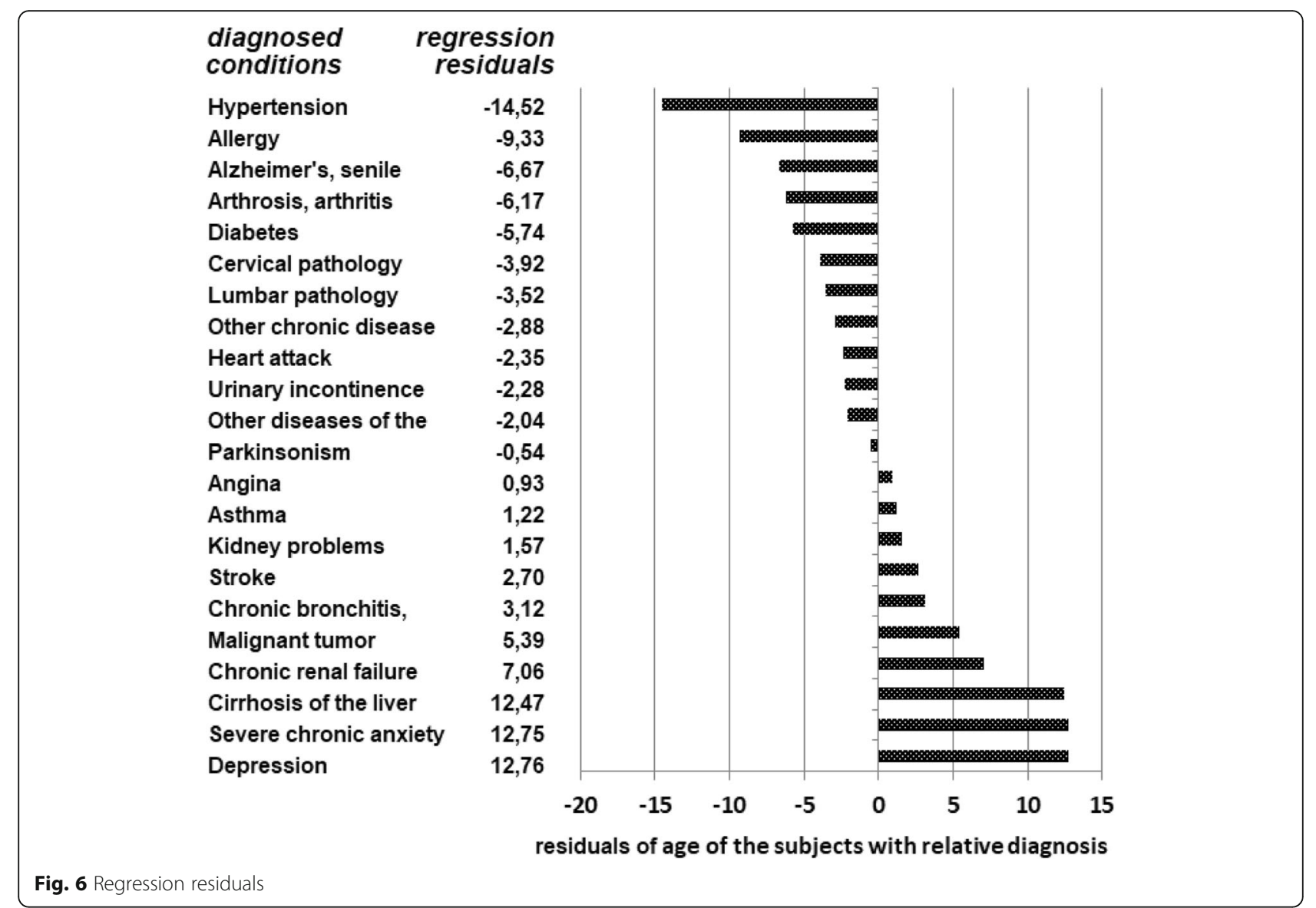

disease than by people's belief of being in a poor health state. Integrating SRH status survey instruments within studies would help the Italian national health system allocate resource more effectively, contributing to predicting the volume of future medical consultations.

Treatment effectiveness evaluations in Italy tend to focus on objective clinical measures of disease. This preference is due to both the fact these measures are often considered easier to quantify and interpret, as well as the fact that self-rated measures do not have the same aura of "medical expertise" [48]. A considerable body of literature is emerging on the importance of integrating measures of patient reported experience and patient reported outcomes as part of a National Health System effectiveness evaluations [49-51]. Drawing from that literature, we suggest that SRH measures can be critically important for the Italian national health system, as they allow to measure what matters to the people that the system is supposed to serve: how these people feel. Clinical diagnostic practices are used to compare objective measures (as, for instance, laboratory exams) with subjective accounts of one's medical history. Clinicians know that these are both important and work to integrate them, even when their combined interpretation is not straightforward.
Similarly, in public health, policy-making practices in Italy have the opportunity to combine objective and subjective health indicators to evaluate the effectiveness of the health system from both perspectives: that of medical experts and that of the population.

Finally, we suggest that integrating SRH measures within Italian national health studies would help understand how social determinants - such as income or education - affect SRH on the Italian territory. A national health system concerned with how people feel (not just with what disease they have) would want to address social disparities in SRH, in concertation with policy-makers across other departments in the government.

\section{Conclusion}

In this paper, we have used a subset of Italian respondents from the Health Interview Survey to look at the validity of self-rated health (SRH) as an indicator for equity analysis. We found that SRH measures were independently associated with age, chronic health conditions and functional limitations, three variables that had a summative effect on SRH. We also found that SRH 
Table 4 Odd ratios of having received at least one medical consultation in the last month, have been hospitalised in the last 12 months, or have received drug prescription in the last 15 days

\begin{tabular}{|c|c|c|c|c|c|c|c|c|c|}
\hline & \multicolumn{3}{|c|}{$\begin{array}{l}\text { Received at least one medical specialist } \\
\text { consultation in the four weeks }\end{array}$} & \multicolumn{3}{|c|}{$\begin{array}{l}\text { Hospitalized at least once in } \\
\text { the last year }\end{array}$} & \multicolumn{3}{|c|}{$\begin{array}{l}\text { Received drug prescriptions in the } \\
\text { last two weeks }\end{array}$} \\
\hline & \multirow[t]{2}{*}{$\overline{O R}$} & \multicolumn{2}{|c|}{ 95\% C.I. } & \multirow[t]{2}{*}{$\overline{\mathrm{OR}}$} & \multicolumn{2}{|c|}{ 95\% C.I. } & \multirow[t]{2}{*}{$\overline{\mathrm{OR}}$} & \multicolumn{2}{|c|}{ 95\% C.I. } \\
\hline & & lower & upper & & lower & upper & & lower & upper \\
\hline \multicolumn{10}{|l|}{ Chronic Diseases } \\
\hline Asthma & 1199 & 1194 & 1203 & 1132 & 0,921 & 1391 & 1255 & 1067 & 1476 \\
\hline Chronic bronchitis & 1267 & 1262 & 1271 & 1204 & 1010 & 1437 & 1152 & 0,986 & 1347 \\
\hline Myocardial infarction & 1490 & 1483 & 1498 & 1981 & 1585 & 2477 & 1879 & 1450 & 2434 \\
\hline Angina pectoris & 1275 & 1269 & 1281 & 1642 & 1332 & 2024 & 1019 & 0,814 & 1277 \\
\hline Hypertension & 1200 & 1198 & 1202 & 1005 & 0,894 & 1129 & 2692 & 2484 & 2917 \\
\hline Stroke & 0,904 & 0,899 & 0,909 & 1636 & 1263 & 2121 & 1007 & 0,751 & 1350 \\
\hline Arthrosis and arthritis & 1131 & 1129 & 1133 & 0,940 & 0,827 & 1067 & 1203 & 1097 & 1320 \\
\hline Diabetes & 1374 & 1370 & 1377 & 1111 & 0,955 & 1292 & 1503 & 1321 & 1711 \\
\hline Cirrhosis of the liver & 0,587 & 0,579 & 0,595 & 1898 & 1054 & 3421 & 0,978 & 0,505 & 1893 \\
\hline Kidney failure & 1246 & 1239 & 1254 & 1576 & 1174 & 2115 & 1162 & 0,834 & 1619 \\
\hline Depression & 1455 & 1449 & 1460 & 0,875 & 0,709 & 1079 & 1709 & 1413 & 2067 \\
\hline Chronic anxiety & 0,902 & 0,898 & 0,906 & 1339 & 1064 & 1685 & 1252 & 0,999 & 1570 \\
\hline Malignant tumour & 2567 & 2556 & 2579 & 3126 & 2547 & 3837 & 1724 & 1375 & 2162 \\
\hline Alzheimer's disease & 0,756 & 0,751 & 0,761 & 0,883 & 0,660 & 1181 & 1244 & 0,911 & 1699 \\
\hline Parkinson's disease & 0,972 & 0,963 & 0,981 & 0,764 & 0,485 & 1203 & 1149 & 0,702 & 1882 \\
\hline \multicolumn{10}{|l|}{ Self-rated health } \\
\hline Very well & 0,635 & 0,633 & 0,637 & 0,500 & 0,397 & 0,630 & 0,509 & 0,459 & 0,564 \\
\hline Well & 1 & - & - & 1 & - & - & 1 & - & - \\
\hline Fair & 1681 & 1678 & 1684 & 1981 & 1744 & 2251 & 1734 & 1603 & 1875 \\
\hline Bad & 3105 & 3095 & 3114 & 4254 & 3601 & 5026 & 2310 & 1997 & 2671 \\
\hline Very bad & 2455 & 2442 & 2467 & 6087 & 4756 & 7791 & 2352 & 1795 & 3082 \\
\hline \multicolumn{10}{|l|}{ Demographics } \\
\hline $30-34$ & 1 & - & - & 1 & - & - & 1 & - & - \\
\hline $35-39$ & 0,995 & 0,991 & 0,999 & 1411 & 1026 & 1941 & 1040 & 0,876 & 1235 \\
\hline $40-44$ & 0,970 & 0,966 & 0,974 & 1114 & 0,814 & 1524 & 1203 & 1025 & 1412 \\
\hline $45-49$ & 0,974 & 0,970 & 0,978 & 1158 & 0,854 & 1571 & 1302 & 1112 & 1523 \\
\hline $50-54$ & 1057 & 1053 & 1061 & 1037 & 0,762 & 1410 & 1447 & 1237 & 1693 \\
\hline $55-59$ & 0,941 & 0,937 & 0,945 & 1204 & 0,888 & 1633 & 1805 & 1539 & 2118 \\
\hline $60-64$ & 0,973 & 0,969 & 0,977 & 1448 & 1072 & 1956 & 2211 & 1880 & 2600 \\
\hline $65-69$ & 1018 & 1014 & 1022 & 1248 & 0,920 & 1692 & 2338 & 1981 & 2759 \\
\hline $70-74$ & 1033 & 1029 & 1038 & 1573 & 1156 & 2140 & 2567 & 2153 & 3061 \\
\hline $75-79$ & 0,970 & 0,966 & 0,975 & 1456 & 1067 & 1988 & 2692 & 2237 & 3240 \\
\hline $80-84$ & 1067 & 1062 & 1072 & 1714 & 1247 & 2356 & 2669 & 2181 & 3268 \\
\hline $85+$ & 0,761 & 0,757 & 0,764 & 1782 & 1291 & 2460 & 2695 & 2179 & 3333 \\
\hline \multicolumn{10}{|l|}{ Sex } \\
\hline Male & 1 & - & - & 1 & - & - & 1 & - & - \\
\hline Female & 1396 & 1394 & 1399 & 0,931 & 0,841 & 1031 & 1299 & 1219 & 1384 \\
\hline \multicolumn{10}{|l|}{ Geographic area } \\
\hline North west & 1 & - & - & 1 & - & - & 1 & - & - \\
\hline North East & 1022 & 1020 & 1025 & 1025 & 0,887 & 1183 & 1153 & 1053 & 1263 \\
\hline
\end{tabular}


Table 4 Odd ratios of having received at least one medical consultation in the last month, have been hospitalised in the last 12 months, or have received drug prescription in the last 15 days (Continued)

\begin{tabular}{|c|c|c|c|c|c|c|c|c|c|}
\hline & \multicolumn{3}{|c|}{$\begin{array}{l}\text { Received at least one medical specialist } \\
\text { consultation in the four weeks }\end{array}$} & \multicolumn{3}{|c|}{$\begin{array}{l}\text { Hospitalized at least once in } \\
\text { the last year }\end{array}$} & \multicolumn{3}{|c|}{$\begin{array}{l}\text { Received drug prescriptions in the } \\
\text { last two weeks }\end{array}$} \\
\hline & \multirow[t]{2}{*}{$\overline{\mathrm{OR}}$} & \multicolumn{2}{|c|}{ 95\% C.I. } & \multirow[t]{2}{*}{$\overline{\mathrm{OR}}$} & \multicolumn{2}{|c|}{ 95\% C.I. } & \multirow[t]{2}{*}{$\overline{O R}$} & \multicolumn{2}{|c|}{ 95\% C.I. } \\
\hline & & lower & upper & & lower & upper & & lower & upper \\
\hline Centre & 0,996 & 0,994 & 0,999 & 0,937 & 0,809 & 1085 & 1019 & 0,928 & 1118 \\
\hline South & 0,693 & 0,692 & 0,695 & 0,798 & 0,690 & 0,922 & 0,865 & 0,790 & 0,947 \\
\hline Islands & 0,814 & 0,811 & 0,816 & 0,960 & 0,805 & 1146 & 0,750 & 0,667 & 0,844 \\
\hline
\end{tabular}

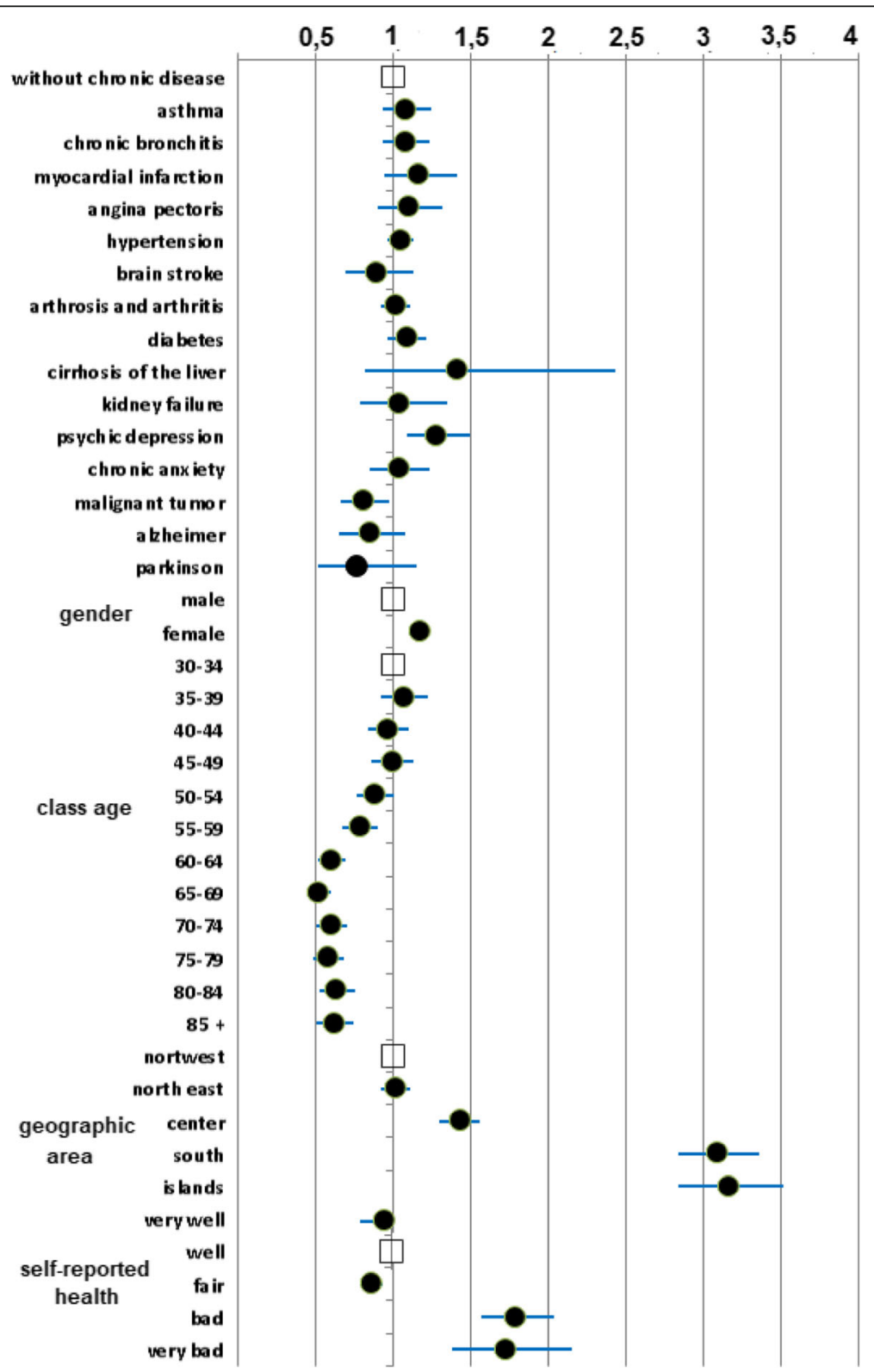

Fig. 7 Logistic regression of the risk of being in the lowest two income quintiles by age, sex, geographic area, chronic health conditions, and self-rated health 
could predict hospitalisation and specialist consultation better than diagnosed health conditions. Finally, we found that SRH was more significantly associated with income than actual diagnosed health conditions.

Our findings suggest that integrating SRH measures within national health studies and policy-making will help Italian health policy-makers in three ways. Firstly, SRH measures will help predict healthcare demand and allocate resources across the national healthcare system more effectively. Secondly, SRH measures will also help assess the subjective effectiveness of the treatment offered by the national healthcare system. Finally, SRH measures will help identify areas of inequity that require special attention.

A national health system able to integrate SRH measures within its indicators for policy-making will be in a better position to achieve its mission of helping people feel well. We look forward to a national health system increasingly concerned with people's feeling of wellbeing and not simply with their diseases.

\section{Abbreviations}

CHC: Chronic Health Conditions; FL: Functional Limitations; H: Hospitalisation; HIS: Health Interview Survey; MSC: Medical Specialist Consultations; MU: Medicine Use; PEl: Household Income; SRH : Self-Rated Health

\section{Acknowledgments}

We are grateful to the two anonymous reviewers who helped us make the manuscript stronger.

\section{Funding}

Funding were granted by the Italian Ministry of Health through the National Agency for Regional Health Services (AGENAS) (Award number n/a).

\section{Availability of data and materials}

The data that support the findings of this study are available from ISTAT, but restrictions apply to the availability of these data, which were used under license for the current study, and so are not publicly available. Data are however available from the authors upon reasonable request and with permission of ISTAT.

\section{Authors' contributions}

$\mathrm{BC}$ led the literature review and the initial drafting of the manuscript. CC conducted the data analysis. Both authors ideated, revised, and approved the manuscript.

\section{Ethics approval and consent to participate \\ N/A}

\section{Consent for publication}

$\mathrm{N} / \mathrm{A}$

\section{Competing interests}

The authors declare that they have no competing interests.

\section{Publisher's Note}

Springer Nature remains neutral with regard to jurisdictional claims in published maps and institutional affiliations.

\section{Author details}

'Department of Global Health and Development, London School of Hygiene and Tropical Medicine, 15-17 Tavistock Place, London WC1 9SH, UK. ${ }^{2}$ Agenzia Nazionale per i Servizi Sanitari Regionali, Rome, Italy.
Received: 12 October 2018 Accepted: 16 April 2019

Published online: 09 May 2019

\section{References}

1. Miilunpalo S, Vuori I, Oji P, Pasanen M, Urponen H. Self-rated health status as a health measure: the predictive value of self-reported health status on the use of physician services and on mortality in the working-age population. J Clin Epidemiol. 1997;50(5):517-28.

2. Krause NM, Jay GM. What do global self-rated health items measure? Med Care. 1994:930-42

3. Bjorner JB, Fayers P, Idler E. Self-rated health. Assessing quality of life; 2005. p. 309-23.

4. GL M, EB D. Self-assessment of health: a longitudinal study of elderly subjects. J Health Soc Behav. 1973;14(1):87-93.

5. Burström B, Fredlund P. Self rated health: is it as good a predictor of subsequent mortality among adults in lower as well as in higher social classes? J Epidemiol Community Health. 2001;55:836-40.

6. Fayers PM, Sprangers MAG. Understanding self-rated health. Lancet. 2002; 359(9302):187-8.

7. Bellon JA. Validity of self reported utilisation of primary health care services in an urban population in Spain. J Epid Comm Health. 2000;54:544-51.

8. Vie TL, Hufthammer $\mathrm{KO}$, Holmen TL, Meland E, Breidablik HJ. Is self-rated health a stable and predictive factor for allostatic load in early adulthood? Findings from the Nord Trondelag health study (HUNT). Soc Sci Med. 2014;117:1-9.

9. Bombak AE. Self-rated health and public health: a critical perspective. Front Public Health. 2013:1:1-4.

10. Sen A. Health: perception versus observation. BMJ. 2002;324(7342):860-1.

11. Barsky A, Cleary P, Klerman G. Determinants of perceived health status of medical outpatients. Soc Sci Med. 1992;42:141-5.

12. Fylkesnes K, Førde O. Determinants and dimensions involved in selfevaluation of health. Soc Sci Med. 1992:35:271-9.

13. Roudijk B, Donders R, Stalmeier P. Cultural values: can they explain selfreported health? Qual Life Res. 2017;26(6):1531-9.

14. von dem Knesebeck O, Dragano N, Siegrist J. Social capital and self-rated health in 21 European countries. GMS Psycho-Social-Medicine. 2005;2: Doc02.

15. Caroli E, Weber-Baghdiguian L. Self-reported health and gender: the role of social norms. Soc Sci Med. 2016;153:220-9.

16. Zajacova A, Huzurbazar S, Todd M. Gender and the structure of self-rated health across the adult life span. Soc Sci Med. 2017;187:58-66.

17. Hosseinpoor AR, Williams JS, Amin A, IAd C, Beard J, Boerma T, et al. Social determinants of self-reported health in women and men: understanding the role of gender in population health. PLoS One. 2012;7(4):1-9

18. Blaxter M. Self-definition of health status and consulting rates in primary care. Q J Soc Aff. 1985;1(2):131-71.

19. Wu S, Wang R, Zhao Y, Ma X, Wu M, Yan X, et al. The relationship between self-rated health and objective health status: a population-based study. BMC Public Health. 2013:13(320):1-9.

20. Haddock CK, Poston WS, Pyle SA, Klesges RC, Weg MW, Peterson A, et al. The validity of self-rated health as a measure of health status among young military personnel: evidence from a cross-sectional survey. Health Qual Life Outcomes. 2006;4:57.

21. Cohen G, Forbes J, Garraway M. Interpreting self reported limiting long-term illness. Br Med J. 1995;311:722-4.

22. Sutton M, Carr-Hillb R, Gravellea H, Riceb N. Do measures of self-reported morbidity bias the estimation of the determinants of health care utilisation? Soc Sci Med. 1999:49:867-78.

23. Gr W. Self-rated health in general practice: a plea for subjectivity. $\mathrm{Br} J \mathrm{Gen}$ Pract. 2015:65(632):110-1.

24. van Hooft S. Health and subjectivity. Health. 1997;1(1):23-36.

25. Marinker M. Why make people patients? J Med Ethics. 1975;1(2):81-4.

26. Misselbrook D. W is for wellbeing and the WHO definition of health. $\mathrm{Br}$ J Gen Pract. 2014;64(628):582.

27. Boyd KM. Disease, illness, sickness, health, healing and wholeness: exploring some elusive concepts. Medical Humanities. 2000;26(1):9-17.

28. Sodergren M, Sundquist J, Johansson SE, Sundquist K. Physical activity, exercise and self-rated health: a population-based study from Sweden. BMC Public Health. 2008:8:352.

29. Reyes-Ortiz CA, Pelaez M, Koenig HG, Mulligan T. Religiosity and self-rated health among Latin American and Caribbean elders. Int J Psychiatry Med. 2007;37(4):425-43. 
30. Darker CD, Donnelly-Swift E, Whiston L, Moore F, Barry JM. Determinants of self-rated health in an Irish deprived suburban population - a cross sectional face-to-face household survey. BMC Public Health. 2016;16(1):767.

31. Stanojević Jerković O, Sauliūnè S, Šumskas L, Birt CA, Kersnik J. Determinants of self-rated health in elderly populations in urban areas in Slovenia, Lithuania and UK: findings of the EURO-URHIS 2 survey. Eur J Pub Health. 2017;27(suppl_2):74-9.

32. PAd S. Individual and social determinants of self-rated health and wellbeing in the elderly population of Portugal. Cadernos de Saúde Pública. 2014;30:2387-400.

33. Jordan K, Ong BN, Croft P. Previous consultation and self reported health status as predictors of future demand for primary care. J Epidemiol Community Health. 2003.

34. Manning WG, Newhouse JP, Ware JE. The status of health in demand estimation; or beyond excellent, good, fair, and poor. In: Fuchs V, editor. Economic aspects of health. New York: NBER; 1982.

35. George PP, Heng BH, Molina JADC, Wong LY, Lin NCW, Cheah JTS. Selfreported chronic diseases and health status and health service utilization results from a community health survey in Singapore. Int J Equity Health. 2012;11(44):1-7.

36. Hunt SM, McKenna SP, McEwen J, Williams J, Papp E. The Nottingham health profile: subjective health status and medical consultations. Soc Sci Med A. 1981;15(3, Part 1):221-9.

37. Atella $V$, Brindisi F, Debe P, Rosati FC. Determinants of access to physician services in Italy: a latent class seemingly unrelated probit approach. Health Econ. 2004;13:657-68.

38. Wilkinson R. Unhealthy societies: the afflictions of inequality. London: Rutledge; 1996.

39. Lahelma E, Martikainen P, Laaksonen M, Aittomaki A. Pathways between socioeconomic determinants of health. J Epidemiol Community Health. 2004;58(4):327-32.

40. Ecob R, Davey Smith G. Income and health: what is the nature of the relationship? Soc Sci Med. 1999;48(5):693-705.

41. Mantzavinis GD, Trikalinos TA, Dimoliatis ID, loannidis JP. Self-reported health in high and very high incomes. Qual Life Res. 2006;15(3):547-58.

42. European Commission. Eurostat: European health interview survey (EHIS wave 2). Methodological manual. Luxembourg: European Commission; 2013 ,

43. Koponen P, Aromaa AJRol, European survey experiences, recommendations. Teoksessa Aromaa AKP, Tafforeau J, Vermeire C, Primatesta P, Marmot M, Kurth B, Gargiulo L, Lehto-Järnstedt US, Räty, S. Health surveys: evaluation, B rKj. Survey Design and methodology in national health interview and health examination surveys 2017;16.

44. Fabrizi E, Ferrante MR, Pacei S, Trivisano C. Hierarchical Bayes multivariate estimation of poverty rates based on increasing thresholds for small domains. Comput Stat Data Anal. 2011;55:1736-47.

45. InGr T. Income composition and inequalities in Hungary,1987-20031. TÁRKI Social Report. 2005;3:72-92.

46. Desesquelles AF, Egidi V, Salvatore MA. Why do Italian people rate their health worse than French people do? An exploration of cross-country differentials of self-rated healthq. Soc Sci Med. 2009:68:1124-8.

47. Kelly BD, Sorin GM, Barry JM, Whiston L, Donnelly-Swift E, Darker C. Community-based, cross-sectional study of self-reported health in postrecession Ireland: what has changed? QJM. 2018.

48. Patrick DL, Y-p C. Measurement of health outcomes in treatment effectiveness evaluations: conceptual and methodological challenges. Med Care. 2000;38(9):I114-25.

49. Black N, Varaganum M, Hutchings AJBQS. Relationship between patient reported experience (PREMs) and patient reported outcomes (PROMs) in elective surgery. 2014;23(7):534-542.

50. Hodson M, Andrew S, Roberts CMJB. Towards an understanding of PREMS and PROMS in COPD. Breathe. 2013;9(5):358-64.

51. Nilsson E, Orwelius L, Kristenson M. Patient-reported outcomes in the swedish national quality registers. J Intern Med. 2016;279(2):141-53.

Ready to submit your research? Choose BMC and benefit from:

- fast, convenient online submission

- thorough peer review by experienced researchers in your field

- rapid publication on acceptance

- support for research data, including large and complex data types

- gold Open Access which fosters wider collaboration and increased citations

- maximum visibility for your research: over $100 \mathrm{M}$ website views per year

At BMC, research is always in progress.

Learn more biomedcentral.com/submissions 